\title{
The Prevalence of Use of Areca Nut and Its Effect on Oral Health in School Going Children in Gadap Town, Malir, Karachi, Pakistan
}

\author{
${ }^{1}$ Mohammad Ali Leghari, ${ }^{2}$ Sajjad Ali, ${ }^{3}$ Sana Maqbool
}

\section{ABSTRACT}

Background: Areca nut chewing in different forms is getting more prevalent among the south Asian inhabitants. Its uses are progressing from adults to adolescents and especially its frequent use among the school going children. The aim of this study was to analyze the prevalence of areca nut chewing and its effect on the oral health of school going children.

Materials and methods: A cross-sectional study using a close ended questionnaire was conducted to collect the data from the school going children of Gadap town, Malir, Karachi. A random sample of 285 students $(n=285)$ were examined. The research instrument was self-structured close ended questionnaire. The questionnaire contained questions regarding the knowledge and consequences of chewing areca nut, its products and its effect on their oral health. The questionnaires were administered to the students in their respective classes and the filled questionnaires were collected on the same day. Chi-square test was used for differences in frequencies among the types of areca nut, practices of using areca nut and gender variables. Stata 11 was used for data analysis. Total number of 285 children were surveyed.

Results: There were $75.09 \%$ boys and $24.91 \%$ girls, mean age of the students was 6.23 (1.05). The range of the students was 4 to 8 years. The frequency of using areca nut and products containing areca nut in our study was $77.9 \%$. There were $60.35 \%$ students both male and female who were identified to gutkha chewing habit. Frequency of consumption of chewing areca nut made products increases as the age's increases. The $74.38 \%$ respondents were suffering from oral lesions.

Conclusion: Chewing of areca nut and products containing areca nut is prevailing in rural areas especially among the lower age group of school going children. Both genders are equally and frequently use areca nut as habit.

Keywords: Areca nut, Gutkha, Rural area, School going children.

\footnotetext{
${ }^{1}$ Assistant Professor, ${ }^{2}$ Registrar, ${ }^{3}$ Demonstrator

${ }^{1}$ Department of Community Dentistry, Baqai Dental College Baqai Medical University, Karachi, Pakistan

${ }^{2}$ Department of Prosthetic Dentistry, Baqai Dental College, Baqai Medical University, Karachi, Pakistan

${ }^{3}$ Department of Dental Education, Baqai Dental College Karachi, Pakistan
}

Corresponding Author: Mohammad Ali Leghari, Assistant Professor, Department of Community Dentistry, Baqai Dental College, Baqai Medical University, Near Toll Plaza, Karachi Pakistan, Phone:00923212141488, e-mail:dralileghari@gmail.com
How to cite this article: Leghari MA, Ali S, Maqbool S. The Prevalence of Use of Areca Nut and Its Effect on Oral Health in School Going Children in Gadap Town, Malir, Karachi, Pakistan. World J Dent 2016;7(1):6-9.

Source of support: Nil

Conflict of interest: None

\section{INTRODUCTION}

Areca nut or 'Chalia' in Urdu language is derived from the palm of areca catechu and it is consumed in the form of baked, raw, or soaked slices of the areca nut, sometimes chewed alone and sometimes along with the betel quid. ${ }^{1}$ Ever since the introduction of tobacco in South Asia, its consumption became increasingly popular among the masses. Recent surveys show that since the last two decades, almost $20 \%$ population from Pakistan, India, and Nepal has been using areca nut habitually ${ }^{2}$ and other forms of tobacco, betel quid, and areca nut are also being used in different parts of the world. ${ }^{3}$

Gutkha is a form of habitual chewing product which is prepared with a mixture of large amount of areca nut and some other ingredients like slaked lime (calcium oxide and calcium hydroxide), catechu and tobacco. It is widely consumed by the teenagers due to its addictiveness, therefore, initiatives have been taken in the most affected provinces of India to ban these products as they are potentially carcinogenic. ${ }^{2,4}$

Risk of using gutkha has been strongly associated with oral submucous fibrosis (OSF) ${ }^{5,6}$ Its chewing starts at a very early age due to the presence of sweeteners in it which attracts the children to use this product as a sweet mouth freshener eventually turning them addictive.

Active alkaloid arecoline ingredient present in the areca nut increases the fibroblast production for collagen formation which can lead to OSF.,8 It has been estimated that one in three children in the Indian subcontinent are frequent users of gutkha. ${ }^{9}$ Its popularity is also on the rise in Pakistan and India because of its easy availability in sachets and as it is easy to carry. ${ }^{10}$ This could be the probable reason for the increase in the prevalence of oral lesions and OSF in school going children of South Asia. ${ }^{11}$

In Pakistan, incidence of areca nut products has risen substantially in school going children. A previous study performed in Karachi shows an alarming situation where 
$94 \%$ adolescents were users of areca nut ${ }^{12}$ and, in another study performed in Karachi, it has been reported that the frequency of areca nut usage was $48 \%$ and it was most prevalent among children between the ages of 6 and $11 .^{13}$

Little data are present in the literature from this particular region regarding the prevalence of areca nut chewing and its effect on the oral health of children. Therefore, this study was carried out to evaluate the frequency of areca nut usage and its effect on the oral health of school going children living in the outskirts of Karachi.

\section{MATERIALS AND METHODS}

A cross-sectional study was carried out to collect the data from school going children through a questionnaire living in Gadap town, Malir, Karachi, Pakistan. Convenience sampling method was used for the collection of data through a newly designed self-structured close ended questionnaire. The questionnaire contained questions aimed at acquiring the knowledge and consequences of chewing areca nut and its products and its effect on the oral health of respondents. The questionnaire was translated into Urdu language and distributed to all the students between grades 1 to 6 present on the day of study. The questionnaires were completed by the children in the presence of a professional dentist who helped the respondents in clarifying their doubts. The filled questionnaires were collected on the same day. A written informed consent was taken from the parents of all the school children 1 week in advance before commencing the study. The principal of the school also gave written permission before the study was initiated. Statistical software Stata 11 was used for data entry and analysis. Simple descriptive statistics, such as frequencies, percentages, means and standard deviations were calculated. Chi-square test and Fisher's exact test were used to assess any statistically significant differences, and the level of significance was set at $p<0.05$.

\section{RESULTS}

Out of 285 school children surveyed, 214 (75.09\%) were boys and 71 (24.91\%) were girls. Mean age of students children was 6.23 (1.05) years. Mean age of boys and girls was 6.33 (1.15) and $5.94(0.53)$ years respectively. The range of the student's ages was 4 to 8 years.

Out of total number of students, there were 222 (77.9\%) students who were habitual chewer of areca and products containing areca nut. Data showed that frequency of boys were higher in numbers of chewing areca nut than compare to girls and the difference of chewing habits of areca nut and containing products was statically significantly different. It has also been observed that there were more than $50 \%$ students addicted to gutkha chewing habit presented in Table 1.

Facts of statistics for children also revealed that students also suffering from altered oral health problems from the areca nut use. There were 212 (74.38\%) students who had oral health problems and the results were statistically different between gender categories, presented in Table 2.

The proportion of respondents who say tobacco is harmful for oral health were $36.14 \%$, more than two-third of the students were unaware from the negative effects of the tobacco consumption. The overall results regarding knowledge and practice of areca in relation to gender presented in Table 3.

\section{DISCUSSION}

The purpose of this study was to explore the frequency pattern of areca nut chewing habits, especially to observe the chewing of gutkha in the remote places of Karachi city, where the resources of primary healthcare, especially oral healthcare facilities were in scarcity. There is lacks of developed infrastructure in these remote places, and therefore, people are involved in labor jobs for their income stability. Low socioeconomic conditions are

Table 1: Prevalence of areca nut habit among boys and girls of study participants $(n=285)$

\begin{tabular}{lllll}
\hline & Total & Male & Female & \\
Types of nuts & $n=285(\%)$ & $n=214(75.09)$ & $n=71(24.91)$ & $p$-value \\
\hline Betel quid with tobacco & $9(3.16 \%)$ & $9(4.21)$ & $0(0)$ & $<0.001$ \\
Areca nut & $40(14.04 \%)$ & $6(2.80)$ & $34(47.89)$ & \\
Gutkha & $173(60.70 \%)$ & $162(76.7)$ & $11(15.49)$ \\
Nonusers & $63(22.11 \%)$ & $37(17.29)$ & $26(36.62)$ & \\
\hline
\end{tabular}

Table 2: Prevalence and comparison of study participants by symptoms $(n=285)$

\begin{tabular}{lllll}
\hline & Total & Male & Female & \\
Oral presenting complains & $n=285(\%)$ & $n=214(75.09)$ & $n=71(24.91)$ & $p$-value \\
\hline Chewing problem & $44(15.44 \%)$ & $34(15.89 \%)$ & $10(14.08 \%)$ & $<0.001$ \\
Swallowing problem & $7(2.46 \%)$ & $5(2.34 \%)$ & $2(2.82 \%)$ & \\
Mouth pain & $69(24.21 \%)$ & $68(31.78 \%)$ & $23(32.39 \%)$ \\
Burning sensation & $92(32.28 \%)$ & $69(32.24 \%)$ & $35(49.30 \%)$ \\
Not any problem & $73(25.61 \%)$ & $38(16.76 \%)$ & \\
\hline
\end{tabular}


Table 3: Knowledge and practice of areca nut made products by gender $(n=285)$

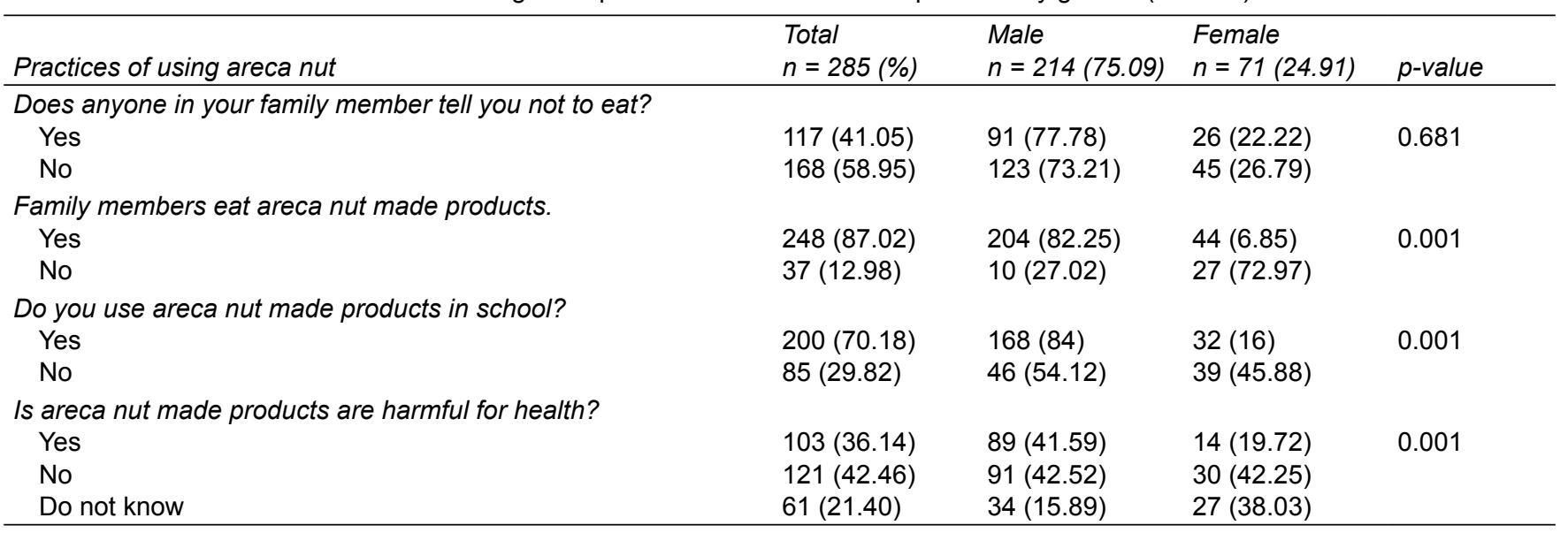

prevalent due to less income and less education of parents, and therefore, parents enroll their children into public schools nearby. Lack of data on chewing habits of early age school going children in the outskirts of Karachi provided the motivation to conduct this study.

The frequency of using areca nut in our study was $77.9 \%$ and the results were comparable to another study conducted in Karachi, Pakistan in 2002 in school children where the $74.2 \%$ children were under the age of 12 years were the users of areca nut. ${ }^{14}$ Furthermore another study done in a high school from Micronesia where the $63 \%$ respondent's showed the prevalence of chewing of areca nut. ${ }^{15}$ As mentioned before, Gupta and Ray in their research discussed the spread of gutkha available toward the rural areas. ${ }^{10}$

In our study, there were $60.35 \%$ students (both male and female) were addicted to gutkha chewing habit. In another research done in a village in Kerala on children between the of 5 and 20 years, the prevalence of betel quid users with tobacco was 13.0 to $16.4 \%$ respectively. ${ }^{16}$ In contrast, our study revealed lower occurrence of users of only areca nut which were $3.16 \%$.

It can be concluded that children are gradually developing the habit of consuming gutkha as the usage of areca nut was not sufficiently satisfying their addiction. The dramatic rise in the chewing habit of gutkha in school children is disquieting. Gutkha predominately replaces the habit of chewing tobacco. It is a known fact that national health agencies would not have acted for the prevention of purchase of gutkha from shops, although a ban has been in place by the government since $2011 .^{17}$

In our study, we have found that consumption chewing habit of areca nut made products per day increases as the age's increases significantly while there was no difference in both sexes. There was significant difference in gender chewing areca nut in our study, in contrary to another research the female portion was predominant in chewing areca nut. ${ }^{18}$
In our study, there were $41 \%$ respondents who told their family members asked them to stop eating in contrast the study done by shah et al where $98.6 \%$ respondent answers that their family members told them to stop the habit of chewing areca nut. ${ }^{12}$ In our research, there were $87.02 \%$ of students family members consume areca nut made products. It has been observed that low education and low income of parents highly associated with relation of children consumption of areca nut and observed in different studies. 19,20

Areca nut consumed with or without tobacco has harmful effects on oral health. Both soft and hard part of the oral cavity affected from the areca nut consumption. The habitual chewers have frequent dental pain due to consistently eating areca nut which lead to dentinal sensitivity sometimes the masticatory forces lead to the fracture of the tooth and unable the person to eat normally. Consistent use of areca nut causes the fibrosis of the lamina propria and the submucosa sometimes the underlying muscles involves which limited the mouth opening. ${ }^{21}$ We have evaluated by self-perceive oral heal problems by using questionnaire, there were $74.38 \%$ respondents were suffering from oral lesions results were dissimilar to the study done in South India where $26.8 \%$ showed oral mucosal changes. ${ }^{22}$ Study done in two areas of Karachi on areca nut users, where respondent mentioned that they have suffered from oral health problems, $40 \%$ reported dental problems. ${ }^{23}$

Convenient sampling method was used although the sample size was not enough, the reason for the selection of one of the school was to familiarize with the surrounding of the location, there was no previous history of data collection and survey of school going children on areca and gutkha chewing found on the dental literature regarding to that area. Ages of the children and parents jobs data were collected from their school registry with kind information of the school head master which could create information bias but this study could unfold the 
prevailing chewing habit of areca nut, there were several types of areca nut containing products were available but they categorized into their primary ingredients. Exact age of starting chewing areca nut and made products from areca nut could lead to recall bias.

\section{CONCLUSION}

Results of the current study showed the prevalence of use of areca nut, especially gutkha among the school going children which was higher. Both genders are using areca nut but male student's frequency of using areca nut and gutkha was higher than female. Results also showed that the areca nut user had adverse effects on their oral health, resulting in low quality of wholesome life. Student's family members were more frequent user of areca nut chewing habit and there were less than $50 \%$ of parents who did not restrict their children for the use of areca nut.

Results also showed that the $70 \%$ of the student's answer positive about their using areca nut made products more frequently in school time.

There is a need for an immediate action plans and policies for the implementation of law against areca nut and gutkha supplies to the young children, which are higher target groups for areca nut manufacturers.

Another limitation of the study was the disproportion of the male and female students, this variation has affected on the selection of gender and distorted the results. The larger proportion of male student's attendees could be due to the socioeconomic statutes of their guardians. Poverty and other religious factors which decline the women to attend the schools were also reported in article from United Nations Educational, Scientific and Cultural Organization (UNESCO) by Latif A. ${ }^{24}$

\section{REFERENCES}

1. Wyk CWV, Stander I, Padayachee A, Grobler-Rabie AF. The areca nut chewing habit and oral squamous cell carcinoma in South African Indians: a retrospective study. S Afr Med J 1993 Jun;83(6):425-429.

2. Sharan RN, Mehrotra R, Choudhury Y, Asotra K. Association of areca nut with carcinogenesis: revisit with a clinical perspective. PLoS ONE 2012;7(8):e42759. DOI: 10.1371/journal. pone.0042759.

3. Gupta PC, Warnakulasuriya S. Global epidemiology of areca nut usage. Addict Biol 2002;7:77-83.

4. Gupta PC, Ray CS. Smokeless tobacco and health in India and South Asia. Respirol 2003 Dec;8(4):419-431.

5. Babu S, Bhat RV, Kumar PU, Sesikaran B, Rao KV, Aruna P, et al. A comparative clinicopathological study of oral submucous fibrosis in habitual chewers of pan masala and betel quid. Clin Toxicol 1996;34:317-322.

6. Madani AH1, Dikshit M, Bhaduri D. Risk for oral cancer associated to smoking, smokeless and oral dip products. Ind J Public Health 2012 Jan-Mar;56(1):57-60.
7. Auluck A, Hislop G, Poh C, Zhang L, Rosin MP. Areca nut and betel quid chewing among South Asian immigrants to Western countries and its implications for oral cancer screening. Rural Remote Health 2009;9(2):1118.

8. Nair U, Bartsch H, Nair J. Alert for an epidemic of oral cancer due to use of the betel quid substitutes gutkha and pan masala: a review of agents and causative mechanisms. Mutagenesis 2004 Jul;19(4):251-262.

9. Changrani J, Gany F. Pan gutkha in the United States: an emerging threat. J Immigr Health 2005 Apr;7(2):103-108.

10. Gupta PC, Ray CS. Tobacco and youth in the South-East Asian region. Ind J Cancer 2002;39(1):1-33.

11. Agrawal A, Airen Sarkar P, Shigli A. Oral submucous fibrosis in a 9-year-old Indian girl. BMJ Case Rep 2011 Sep 28;2011.

12. Shah S, Qureshi R, Azam I. Is Chaalia/pan masala harmful for health? Practices and knowledge of children of schools in Mahmoodabad and Chanesar Goth, Karachi. J Pak Med Assoc 2009 Aug;59(8):550-554.

13. Qureshi A, Dawani N, Shaikh AA. Areca nut consumption patterns among primary school children of Karachi. J Dow Uni Health Sci 2013;7(1):25-29.

14. Shah SMA, Merchant AT, Luby SP, Chotani RA. Addicted schoolchildren: prevalence and characteristics of areca nut chewers among primary school children in Karachi, Pakistan. J Paediatr Child Health 2002;38:507-510.

15. Pobutsky AM, Neri EI. Betelnut chewing in Hawai'i: Is it becoming a public health problem? Historical and sociocultural considerations. Hawai'i J Med and Public Health 2012;71:23-26.

16. Hashibe M1, Jacob BJ, Thomas G, Ramadas K, Mathew B, Sankaranarayanan R, Zhang ZF. Socioeconomic status, lifestyle factors and oral premalignant lesions. Oral Oncol 2003 Oct;39(7):664-671.

17. Chew on this: Three years after ban, the 'Gutkha Mafia' is still active. The Express Tribune [Internet]. 2014 September 1 [cited 2014 Nov 10]. Available at: http://tribune.com. pk/story/756278/chew-on-this-three-years-after-ban-thegutkha-mafia-isstill- active/.

18. Bruijnzeel AW. Tobacco addiction and the dysregulation of brain stress systems. Neurosci Biobehav Rev 2012;36: 1418-1441.

19. Nisar N, Billo N, Gadit AA. Pattern of tobacco consumption amongst adult women of low socioeconomic community Karachi, Pakistan. J Pak Med Assoc 2005;55:111-114.

20. Rani M, Bonu S, Jha P, Nguyen S, Jamjoum L. Tobacco use in India: prevalence and predictors of smoking and chewing in a national cross-sectional household survey. Tob Control 2003;12:12-14.

21. Trivedy CR, Craig G, Warnakulasuriya S. The oral health consequences of chewing areca nut. Addict Biol 2002 Jan; 7(1):115-125.

22. Patil PB, Bathi R, Chaudhari S. Prevalence of oral mucosal lesions in dental patients with tobacco smoking, chewing, and mixed habits: a cross-sectional study in South India. J Family Community Med 2013 May-Aug;20(2):130-135.

23. Khan MS, Bawany FI, Shah SR, Hussain M, Arshad MH, Nisar N. Comparison of knowledge, attitude and practices of areca nut users in two socioeconomic areas of Karachi. J Pak Med Assoc 2013 Oct;63(10):1319-1325.

24. Latif A. Alarming situation of education in Pakistan. Retrieved 24/04/2015, 2015, Available at: http://www.unesco. org/education/efa/know_sharing/grassroots_stories/ pakistan_2.shtml. 